\title{
Perception of Intonational Patterns and Speaker's Intentionality in English Yes-No Questions Produced by Brazilians
}

\author{
Percepção de Padrões Entoacionais e da \\ Intencionalidade dos falantes em Interrogativas \\ Totais do Inglês Produzidas por Brasileiros
}

Leonice Passarella dos Reis

Universidade Federal de Santa Catarina (UFSC), Florianópolis, Santa Catarina, Brasil. leonicepr@gmail.com

Alison Roberto Gonçalves

Universidade Federal de Santa Catarina (UFSC/CNPq), Florianópolis, Santa Catarina, Brasil.

alisonrobertogoncalves@gmail.com

Rosane Silveira

Universidade Federal de Santa Catarina (UFSC/CNPq), Florianópolis, Santa Catarina, Brasil.

rosanesilveira@hotmail.com

Abstract: The current study investigated the perception of different intonational patterns and speaker's intentionality in English yes-no questions produced by Brazilian Portuguese speakers of English. The speakers were six Brazilians who recorded a dialogue. The listeners were 31 Brazilians from different parts of the country who took a Perception of Sentence Modality Test and a Perception of Intentionality Test. Three different contours were tested: English-L1 like, Brazilian-Portuguese like, and Interlanguage like. Results demonstrate that English-L1 like and Brazilian-Portuguese like were generally perceived as yes-no and misperceived as wh-questions, whereas Interlanguage like tended to be mostly perceived as yes-no questions. In the Perception of Intentionality Test, there was a tendency for listeners to consider that the speakers were asking neutral yes-no questions most of the times, which 
somewhat is in tune with the results obtained at the perception test. Speakers' intentions were also interpreted by listeners with much variability, which could have been a test effect.

Keywords: L2 perception; intonational patterns; neutral yes-no questions; intentionality; L2 phonology.

Resumo: O presente estudo investigou a percepção de diferentes padrões entoacionais e da intencionalidade do falante em perguntas interrogativas totais do inglês. Os falantes foram seis brasileiros que gravaram um diálogo. Os ouvintes foram 31 brasileiros de diferentes partes do país que realizaram um Teste de Percepção da Modalidade da Sentença e um Teste de Percepção da Intencionalidade. Três contornos diferentes foram testados: padrão do inglês americano; padrão do português brasileiro; e padrão encontrado na interlíngua dos falantes. Os resultados demonstram que os padrões do inglês americano e do português brasileiro foram geralmente percebidos como interrogativas totais e percebidos inadequadamente como interrogativas $\mathrm{WH}$. O padrão encontrado na interlíngua dos falantes foi na maioria das vezes percebido como interrogativas totais. O Teste de Percepção da Intencionalidade revelou que os ouvintes consideravam que os falantes faziam uso de interrogativas totais na maioria das vezes, o que parcialmente está de acordo com os resultados do teste de percepção. Não obstante, as intenções dos falantes foram interpretadas com muita variabilidade, o que pode ter sido um efeito do teste.

Palavras-chave: percepção em L2; padrões entoacionais; interrogativas totais neutras; intencionalidade; fonologia da L2.

Recebido em: 21 de outubro de 2014. Aprovado em: 23 de janeiro de 2015.

\section{Introduction}

Research on speech perception has started to revolve around issues that are likely to impinge on communication among subjects who speak English as a common additional language in their interactions. Speech perception is a complex task that can be constrained by listeners' 
inexperience in attending to the relevant dimensions of speech that are specific to a determined target language (SMILJANIC; BRADLOW, 2011). Therefore, practitioners in the field of Second Language Acquisition (SLA) have started to shift attention to how speakers from different language backgrounds react to certain speech traits that can affect L2 ${ }^{1}$ speech decoding. In order to shed light on classroom instruction, findings from studies of this nature can provide insight on training techniques and pedagogical materials so that they are developed in a way that students' chances for improvement at different levels are optimized (ZAMPINI, 2008). In addition, more attention is cast on certain speech properties that influence listeners' perception across multiple language backgrounds.

Much L2 research has been conducted on segmentals. However, learners need to be able to succeed at the different levels involved in speech production, including both segmentals and suprasegmentals. Thus, the present study investigates perception of intonational patterns (a dimension related to the suprasegmental level) and intentionality, which is related to the semantic level of the utterances (in other words, the intention behind each question). Firstly, neutral yes-no questions in American English (AE) and in Brazilian Portuguese (BP) are discussed, followed by the dimensions of perception and intentionality. Next, the method of each experiment is demonstrated, followed by the results and a discussion on their findings.

\section{Neutral yes-no questions in Brazilian Portuguese and in American English}

Intonation refers to patterned variation related to units greater than segments, whose acoustic parameters are the F0 curve, that is, the pitch contour (BECKMAN; VENDITTI, 2013), which in research on intonation is often described by means of the Autosegmental Metrical (AM) System, introduced by Pierrehumbert (1980). The AM system has a phonological approach and represents intonation as a sequence of tones

\footnotetext{
${ }^{1}$ L2 refers to any languages acquired after one's first language.
} 
that contrast by their height - low (L) or high $(\mathrm{H})$. It represents the contour as a sequence of pitch accents and edge tones (LADD, 1996, 2008).

The pitch accent can be either $\mathrm{L}$ or $\mathrm{H}$, or a combination of the two (LH, HL). Edge tones are divided into two types: phrase accents and boundary tones; only the latter is used in the patterns investigated in this paper. A phrase accent (or phrase tone) occurs between the last pitch accent tone and the boundary tone, that is, it is the tone that usually precedes the boundary tone; it is the peak (or the valley) at the end of the nuclear word (LADD, 1996). A boundary tone is a tone (L or H) that marks the end of the intonational phrase, in our case, the intonational pattern, and is followed by the diacritic \%. Find below a schema of the notation conventions used in this paper:

$\mathrm{L}^{*}$ - the central tone of a pitch accent is low

$\mathrm{H}^{*}$ - the central tone of a pitch accent is high

$\mathrm{L} \%$ - low boundary tone

$\mathrm{H} \%$ - high boundary tone

$! \mathrm{H} \%$ - a boundary tone that has not reached the necessary height in order to be considered an $\mathrm{H} \%$.

$>$ - indicates that the peak of either tone is aligned at the left margin of the stressed vowel.

$<-$ indicates that the peak of either tone is aligned at the right margin of the stressed vowel.

According to Moraes (2008), the intonational pattern of BP yesno questions has three different possible notations: ${ }^{2}(1) \mathrm{LH}^{*} \mathrm{~L} \%$, (2)

${ }^{2}$ We would like to highlight, however, as commented by one of the reviewers, that these three patterns apply mostly to yes-no questions which end in unstressed syllables (e.g., Você quer chocolate? "Do you want some chocolate?). If the last syllable is stressed (e.g. Você quer chá? "Do you want some tea?", the boundary tone is likely to be an $\mathrm{H} \%$ provided that there is no room for a descending movement. Nevertheless, although the low boundary tone in the three questions ending in syllables with the potential to take stress was not drawn by Praat, Passarella-Reis (2014) found instances in which such descending movement could be heard (eg., Você gosta de rock? "Do you like rock?"). It is definitely an issue which deserves further investigation. 
$\mathrm{L}+>\mathrm{H} * \mathrm{~L} \%{ }^{3}$ and (3) $\mathrm{H}+[\mathrm{LH}] * \mathrm{~L} \%$. The $\mathrm{LH} * \mathrm{~L} \%$ notation represents the intonational pattern of neutral BP yes-no questions, that is, questions that seek unknown pieces of information. The answer to a neutral yes-no question is a piece of totally new information. On the one hand, notations (2) and (3) contrast themselves from one another either by having the $\mathrm{H}$ (high tone) alignment anticipated (2) or by having a high tone $(\mathrm{H})$ in the preceding stressed syllable followed by a fall and then a rise in the stressed syllable (LH*) (3). In both cases (2 and 3), questions are seen as rhetorical questions or requests (2) and as incredulous questions (3) rather than as neutral. On the other hand, the three notations are alike given that they share the same boundary tone (L\%). However, these subtle differences may play a role in identifying the speaker's intentions. Figure 1 illustrates the $\mathrm{LH}^{*} \mathrm{~L} \%$ intonational pattern.

Figure 1 - Neutral BP yes-no question (LH*L\%)

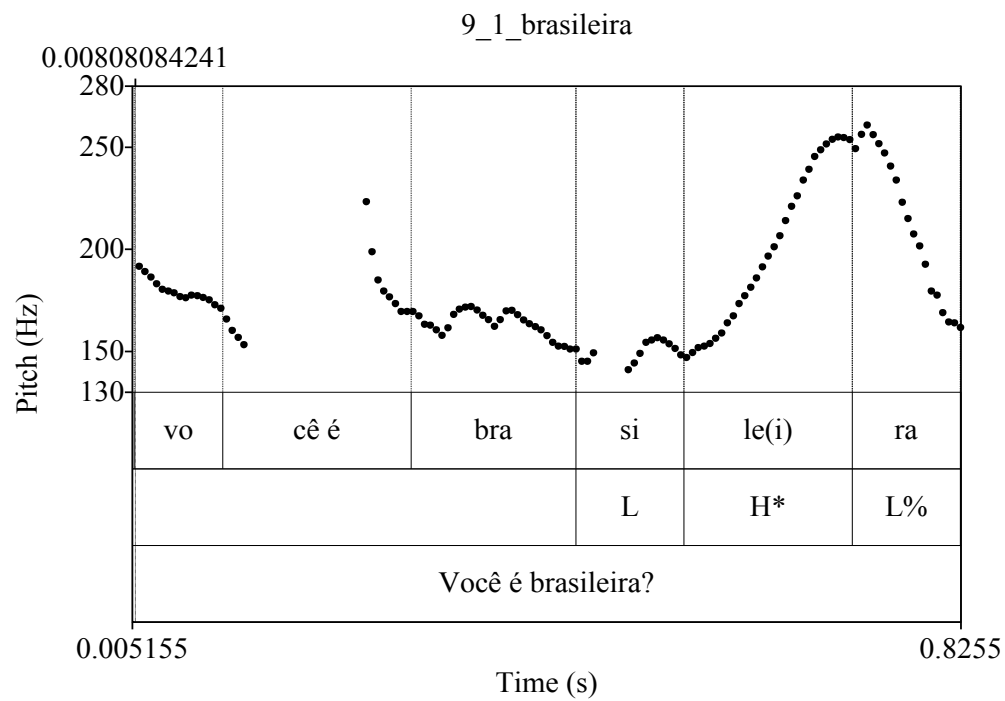

Source: Passarella-Reis (2014).

Hedberg, Sosa and Fadden (2004) highlight four possible intonational contours for positive yes-no questions in North-American

${ }^{3}$ The diacritic $>$ indicates the anticipated alignment of a tone (MORAES, 2008). 
English: (1) $\mathrm{H}^{*} \mathrm{HH} \%$, (2) $\mathrm{H}^{*} \mathrm{LL} \%$, (3) $\mathrm{H}^{*} \mathrm{HL} \%$, and (4) $\mathrm{L} * \mathrm{HH} \%$. The latter represents the melodic contour of neutral yes-no questions in English. The contours (1), (2), and (3) contrast from (4) not only because they have a different boundary tone ( 2 and 3 ), but also because they do not share the same phrase accent and the same pitch accent. The contour represented by the notation $\mathrm{H}^{*} \mathrm{HH} \%$ (1) indicates that the question denotes surprise, that is, it is no longer a neutral / real question. Regarding contours (2) and (3), there is an indication that a positive answer is expected. The phrase tone was left behind for the intonational patterns investigated in Passarella-Reis (2014) whenever it was considered as irrelevant information, that is, when a phrase tone and a boundary tone were the same (SOSA, personal communication), which rendered the following notations: (1) $\mathrm{H}^{*} \mathrm{H} \%$, (2) $\mathrm{H}^{*} \mathrm{~L} \%$, (3) $\mathrm{H}^{*} \mathrm{HL} \%$, and (4) $\mathrm{L} * \mathrm{H} \%$. Figure 2 illustrates the intonational pattern $\mathrm{L} * \mathrm{H} \%$.

Figure 2 - Neutral English yes-no question ( $\mathrm{L} * \mathrm{H} \%$ )

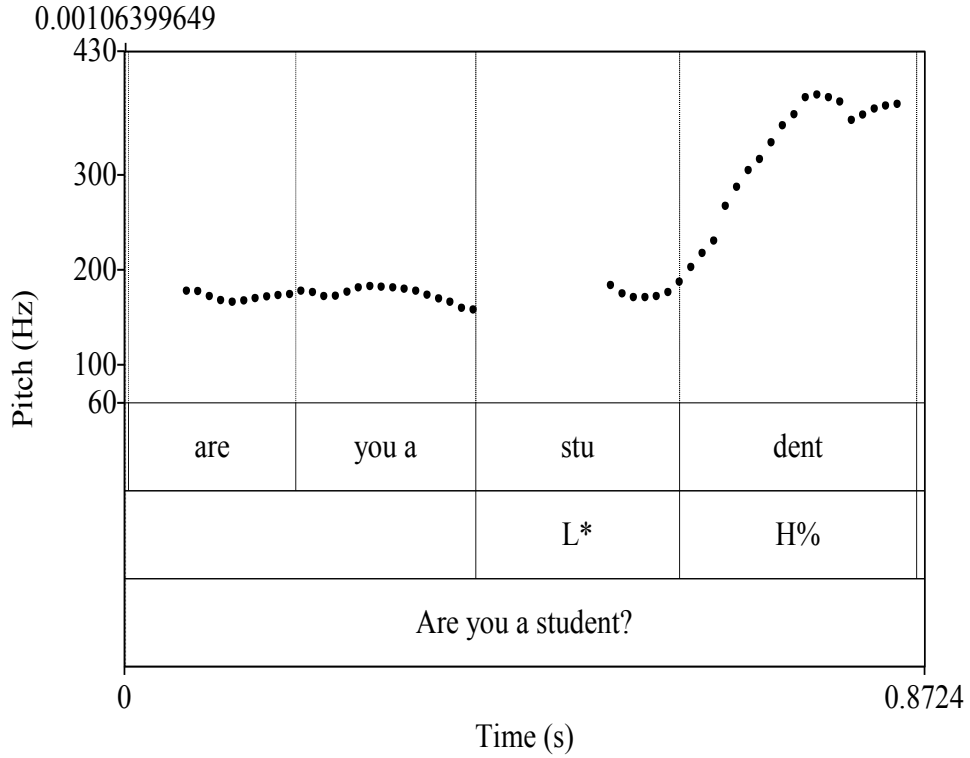

Source: Passarella-Reis (2014). 
Passarella-Reis (2014) found an intonational pattern for neutral yes-no questions produced by BP speakers of English (BPSE), namely, $\mathrm{L} * \mathrm{H} \%$. As highlighted by the scholar, this intonational contour has not been described in the literature hitherto as being representative of a neutral yes-no question ${ }^{4}$ and was, then, considered to represent the BPSE attempt to reach the intonational pattern $\mathrm{L} * \mathrm{H} \%$ (for neutral English yesno questions). The BPSE begin the pitch accent set at low (L), then they start to rise it until they reach the post accented syllable. However, the speakers are unable to go up the necessary amount of $\mathrm{Hz}$ in order to produce a tone that can be considered high $(\mathrm{H})$ and keep that same height until they reach the boundary tone. The diacritic ! here represents this attempt and lack of success. The emergence of this contour was explained as being part of the learner's language which is in constant development. Figure 3 shows an example of this intonational pattern.

Figure 3 - Developing intonational pattern of Neutral AL yes-no questions by BPSE ( $\left.\mathrm{L}^{*} ! \mathrm{H} \%\right)$

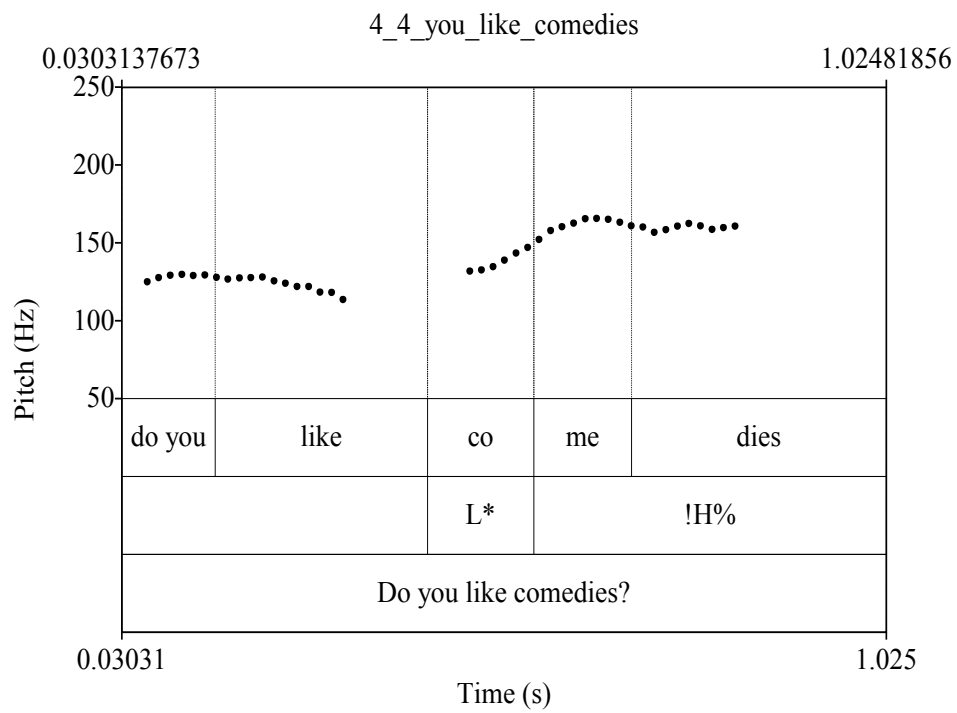

Source: Passarella-Reis (2014).

\footnotetext{
${ }^{4}$ As indicated by one of the reviewers, this intonational pattern may indicate a more polite question.
} 
In addition to $\mathrm{L} * \mathrm{H} \%$, her results showed that BPSE from different proficiency levels also transferred their L1 intonational pattern $\mathrm{LH}^{*} \mathrm{~L} \%$ to their additional language (AL) productions. The author highlights the importance of reaching discernment of the impact of these productions on the comprehension of the intended messages when heard by speakers of English from different nationalities.

Research on yes-no questions have shown that the subtle variations in the intonational patterns may change the meaning of an utterance. In BP, a yes-no question can be understood as a request, basically depending on the alignment of the tone in the stressed syllable. (COLAMARCO; MORAES, 2008). Yes-no questions that have a high boundary tone $(\mathrm{H} \%)$ can be understood as if the speaker is being emphatic (MORAES, 2008), being kind and careful (PASSARELLAREIS, 2014), or expecting a positive answer (SOSA; NUNES; SEARA, 2013). In English, Huynh (2012) describes that yes-no questions can sometimes have an L\% boundary tone which can be interpreted as not being neutral. The speaker may already know the answer and is just making sure whether or not it is correct. Hedberg and Sosa (2011) explain that falling intonation may (1) convey a piece of information (an announcement) rather than a question (Did I tell you I have a new job?), (2) be a request for action (Can we talk about the job things now?), (3) be an observation (Do you have a cold?). Yet, a given yes-no question can be uttered as a totally different intonational pattern, for example, as that of a statement ( $\left.\mathrm{LH}^{*} \mathrm{~L} \%\right)$ in English and be interpreted as if the speaker is assuming what is being uttered, not really asking for that information (PASSARELLA-REIS, 2014). The $\mathrm{LH}^{*} \mathrm{~L} \%$ is a PB intonational pattern for yes-no questions, which Brazilians tend to transfer to the production of yes-no questions in English (PASSARELLA-REIS, 2014). This transfer may mislead the listener who may not respond in an expected neutral fashion and can cause communication discomfort and bias against the speaker.

This section briefly described the intonational patterns of $\mathrm{AE}$ and BP, and it paved the way to the central issues in the present study. Our purpose here is to investigate how BP listeners perceive and interpret speaker's intentions of the $\mathrm{LH}^{*} \mathrm{~L} \%$ (first language) and the 
$\mathrm{L}^{*} ! \mathrm{H}$ (interlanguage) intonational patterns when produced by other BP speakers.

\section{Perception and Intentionality}

Crystal (2008) defines perception as "[...] the process of receiving and decoding spoken, written or signed input. The underlying process is one of matching a set of cues to a stored representation" (CRYSTAL, 2008, p. 356). Thus, as regards perception, language is decoded in favor of a stored representation. Crystal (2008) also remarks that perception is usually related to production, so that it is possible to observe whether learners have already stored an underlying representation for a certain sound that they produce (which takes on the relationship of phonetics and phonology, as well). Auditory perception tasks make use of different types of tests (discrimination, identification, and goodness-of-fit tests, for instance), which present isolated pieces of linguistic information to test for contrasts, where cotextual $l^{5}$ information is not of importance. In the present study, perception is evaluated by using a forced-choice identification test containing decontextualized questions.

Intentionality refers to the speaker's intention that is conveyed by the different tunes ${ }^{6}$ present in the uttered sentence. A given sentence can convey different meanings due to different tunes and, thus, resemble a different attitude of the speaker. Hirschberg et al. (1987) demonstrate that "a yes-no question contour on 'Can you pass the salt?' will be more likely to elicit a direct yes-no response, while a declarative pattern will be more likely to be interpreted as a request to pass the salt" (HIRSCHBERG et al., 1987, p. 638). Likewise, the scholars assert that a yes-no question contour over the sentence "My name is Mark

5 Cotext refers to the items that accompany an item under discussion (CATFORD, 1965).

6 Pierrehumbert and Hirschberg (1990) define tune as "the abstract source of fundamental frequency patterns - the difference between a typical declarative intonation and a question intonation is a tune difference" (PIERREHUMBERT; HIRSCHBERG, 1990, p. 272). 
Liberman?" does not convey a request for a yes-no response - but whether that name was known to the hearer.

Speaker attitude is generally inferred from the choices of the tunes conveyed by an utterance. Different tunes can convey, for instance, presupposition, uncertainty, ignorance, and belief (PIERREHUMBERT; HIRSCHBERG, 1990). Usually, a certain tune can be related to a specific attitude. The question Do you agree? uttered with the intonational pattern $\mathrm{H}^{*} \mathrm{LL} \%$ may be interpreted as an assertion, that is, when uttering Do you agree? the speaker is expecting that the listener will agree to something previously said and is trying to elicit conformation of this (HEDBERG et al., 2004). The study of speaker's intentionality is relevant as it reveals that the suprasegmental level can convey a different meaning from what is expressed at the segmental level. In this piece of research, speakers' intentionality is analyzed by listeners in single utterances.

The present study also investigates how listeners who share the same L1 as the L2 speakers might have an advantage over the comprehension of utterances. This is explained by Bent and Bradlow (2003), who advocate that when listeners and speakers share the same L1, they "are both systematically linked to native language sound structure" (Op. cit., p. 1607). As explained by the authors, speakers' and listeners' linguistic knowledge encompasses aspects of both the L1 and the L2, including "the system of consonant and vowel categories, phonotactics, stress patterns, and intonation as well as other features of the sound system" (Op. cit., p. 1607). In sum, a non-native listener is well equipped to interpret certain acoustic-phonetic features of the L2 speech produced by a non-native listener "even if they deviate markedly from the target forms" (Op. cit., p. 1607). In the present study, both speakers and listeners are Brazilian-Portuguese L1 speakers. This is especially relevant for context in which subjects who share the same L1 are required to interact in the L2, such as international business meetings, bilingual schools and language courses.

After having defined the most important constructs that guide this study, now the research questions and hypotheses are presented, followed by a description of the research method. 


\section{Research questions and Hypotheses}

This paper sets out to investigate how three intonational patterns produced for neutral yes-no questions in English by BPSE are perceived and interpreted by other BPSE. The three intonational patterns are: L*H\% (English-L1 like), LH*L\% (BP like - transferred from BP), and $\mathrm{L}^{*} ! \mathrm{H} \%$ (interlanguage ${ }^{7}$ like). In order to achieve this, the following research questions and hypotheses were set down:

1) How are the developing intonational contours of English yes-no questions produced by BPSE perceived by other BPSE?

H1: Neither $\mathrm{L}^{*} \mathrm{H} \%$ nor $\mathrm{L}^{*} ! \mathrm{H}$ utterances will be perceived as questions.

$\mathrm{H} 2$ : $\mathrm{LH}^{*} \mathrm{~L} \%$ utterances will be perceived as questions.

2) How are the speakers' intentions interpreted by BPSE listeners?

H3: BPSE Listeners will mostly infer that something else rather than the intended message is being conveyed, given that questions under $\mathrm{L} * \mathrm{H} \%$ and $\mathrm{L} * \mathrm{H}$ utterances will probably not be perceived as questions ( $\mathrm{H} 1)$.

H4: Listeners will mostly interpret $\mathrm{LH}^{*} \mathrm{~L} \%$ utterances as neutral questions, and thus they will understand the message as intended.

\section{Method}

5.1 Participants, procedures, and instruments

Participants were 6 speakers and 31 listeners. The speakers were five male Brazilian Portuguese speakers of English (BPSE), and one male North-American speaker of English (NSE), all of whom participated in a previous study by Passarella-Reis (2014).

The five BPSE speakers were all from Rio de Janeiro, where they lived most of their lives. Their age ranged from 18 to 39 years at the time of data collection $(M=26.20)$. They were all military men at the

\footnotetext{
7 "The existence of a separate linguistic system based on the observable output which results from a learner's attempted production of a TL norm. This linguistic system we will call interlanguage" (SELINKER, 1972, p. 214).
} 
Brazilian Navy. At the time of data collection, three out of five were seaman-apprentices in the beginning of their military careers, had never been in an English speaking country, did not speak an additional language other than English, were going through formal English instruction (under 135 minutes to 300 minutes of exposure to English per week). In contrast, the other two BPSE speakers were already officers in the middle of their careers, had already been in English speaking countries, and were no longer under formal instruction of English at the time of data collection.

The BPSE speakers (1) answered a questionnaire designed to collect information about their profiles (e.g., age, origin, knowledge of foreign languages, etc.), (2) signed a Consent Form, (3) performed an oral activity, and (4) recorded, on different days, two versions of the same conversation: an English version on the first day and a Portuguese version on the second day, which generated the stimuli to be used in the present study. ${ }^{8}$ The BPSE speakers were instructed to read each conversation as naturally as possible and one of the researchers acted as the interlocutor, providing answers.

The NSE speaker was monolingual, from California, U.S.A., where he lived most of his life. Data from this informant were collected in a single meeting. The NSE (1) completed a profile questionnaire, (2) signed the Consent Form, and (c) recorded the English version of the same conversation recorded by the BPSE, having his wife as an interlocutor. When data were collected, he was 41 years old, living in Canada, and daily interacted with speakers of English as an AL from two to four hours a day. Data from this native speaker of English were included in the test in order to better understand how the listeners perceived the intonational patterns and the intentionality of utterances that would not contain mispronunciations. Furthermore, these data are expected to provide us with a better understanding of how the listeners perform the two tests and can provide us with insights about the reliability and validity of the tests designed for this study.

\footnotetext{
${ }^{8}$ For detailed information on the procedures for the recording of the samples, please refer to Passarella-Reis (2014).
} 
During the collection of speech data, all participants were asked to read the conversations as naturally as possible. The answers that the interlocutors provided to the participants were not typed in the sheet containing the conversation(s) recorded by the participants. This procedure aimed at having the participants ask neutral questions, giving that they were not aware of the responses and would be eliciting unknown information.

The stimuli encompassed five tokens for each intonational pattern produced by the BPSE - $\left(\mathrm{L}^{*} ! \mathrm{H} \%\right),\left(\mathrm{LH}^{*} \mathrm{~L} \%\right)$, and $(\mathrm{L} * \mathrm{H} \%)$; and 1 token for $\left(\mathrm{LH}^{*} \mathrm{~L} \%\right)$ and one for $(\mathrm{L} * \mathrm{H} \%)$ provided by the NSE, adding up to a total of 17 utterances. In each of the two tests, the NSE samples were presented at the end in order to avoid any bias towards the speakers' accent. Additionally, there was an attempt to avoid repetition of the same questions along each test. Nonetheless, because there was a lack of 17 different questions meeting the three different intonational patterns, two questions had to be repeated. The repetitions were, however, uttered by different speakers and were placed far from their first occurrences, that is, at the end of the tests. These audio files were used to design the Perception of Sentence Modality Test and the Perception of Intentionality Test, which were made available to the listeners at a website especially devised for collecting data.

Listeners were invited to participate through informal advertising (Facebook, e-mail, and personal conversations). Seventy-four people started participating, but only 44 finished the three experiments within the 22 days of data collection and were then considered as participants in this study. They were 31 BPSE, 10 AL speakers of English from different nationalities other than Brazilian (ALSE), and three speakers of English as an L1 (English-L1). The present paper focuses on the data gathered from the 31 BPSE, as our main focus here is to discuss the perception of listeners who share the same $\mathrm{L} 1$ as the speakers.

The 31 BPSE listeners were 10 male and 21 female from different parts of Brazil: Bahia (2), Pará (1), Paraíba (1), Paraná (4), Rio de Janeiro (1), Rio Grande do Norte (1), Rio Grande do Sul (6), Santa Catarina (12), and São Paulo (3). Five BPSE listeners were currently living abroad: one in France, two in the Netherlands, one in Canada, and one in the U.S.A. Only two BPSE listeners reported not being currently 
in touch with English. Thirteen reported they had never been to an English speaking country, while 18 reported they had. Only one listener reported understanding English not well, whilst 7 and 23 reported understanding English fairly well and very well, respectively. Seventeen reported speaking an AL other than English. The BPSE listeners' age ranged from 19 to 49 years $(M=30.06)$. Most of them were teachers of English, or were pursuing a degree in the field.

Listeners accessed a web page put together for data collection. The web page contained a two-part questionnaire, and three different tasks that sought to obtain different perceptual data. Before each task, listeners had some explanation about the tasks and were offered practice trials to get familiar with the tests format. Each of the instruments shall be explained below.

\subsection{Perception of Sentence Modality Test}

The first task was a forced-choice identification test that contained 17 filtered speech samples that presented only suprasegmental information. They were manipulated through Praat, where the filter Hann band was passed so that all linguistic information (which is usually above $300 \mathrm{~Hz}$ ) would be excluded..$^{10}$ Listeners had to decide whether the token sounded like (1) a statement, (2) a wh- question, ${ }^{11}$ or (3) a yes-no question. The options were displayed right after the audio sample, which could be played as many times as the speaker required. The website allowed no randomization of files. The tokens encompassed different intonational patterns produced by a NSE and the five BPSE (see APPENDIX A). Figure 4 provides a snapshot of the Perception of Sentence Modality Test.

9 Cf. $<$ http://www.leonicepassarella.pro.br $>$.

10 Intensity was also increased to $90 \mathrm{~dB}$ so that the volume of the utterances would not become an intervening variable.

11 The wh-question was a distracter, as no intonational pattern for wh-questions were played. 
Figure 4 - An example of a Perception of Sentence Modality Test item

\section{Experiment 1}

You will hear 17 audio files. You have to indicate whether what you hear sounds more like a statement (You're from Japan.), a yes/no question (Are you from Japan?) or a WH-question (Where are you from?), by pushing the corresponding button.

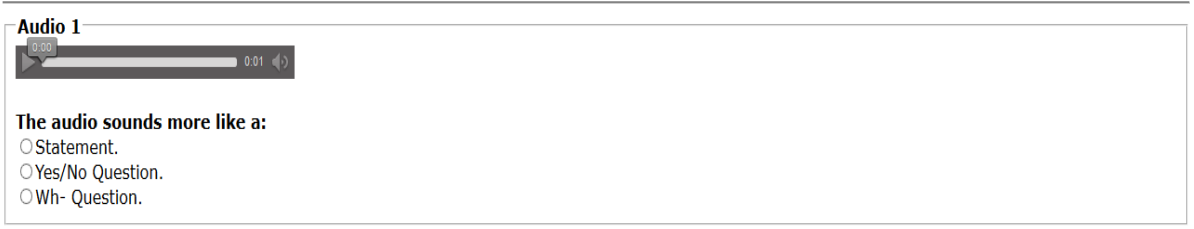

Source: the authors.

\subsection{Perception of Intentionality Test}

The Perception of Intentionality Test was designed to obtain data regarding the mood / intention of the speaker with each utterance presented in the stimuli. Thus, the experimenters could observe how the different intonational patterns presented influenced listeners' perceptions of intention. The 17 speech samples, with no adjustments made, were presented to the listeners. For each token, listeners had to choose the intention / mood of the speaker. Choices were presented, and listeners could insert a new option by typing it, in case they disagreed with the ones presented. Figure 6 illustrates the Perception of Intentionality Test.

Figure 6 - An example of a Perception of Intentionality Test utterance 


\section{Experiment 3}

You will hear the 17 utterances again. This time, your task is to give us your impressions about the speaker of each utterance either by choosing one of the choices given or by writing down words of your own. You can play the audio as many times as you wish.

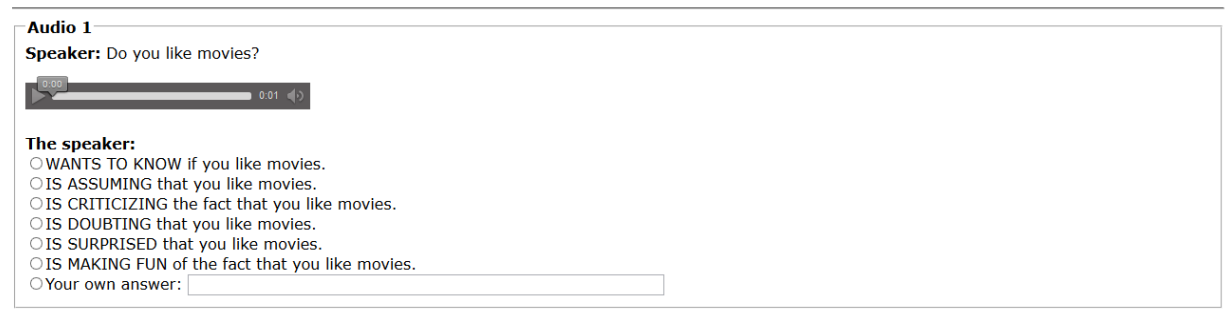

Source: the authors.

\subsection{Questionnaire}

A questionnaire was administered to listeners so that background information could be gathered. Based on Gonçalves (2014), it elicited personal information, as well as information about participants' knowledge of foreign languages, exposure to English, and experience with the BP accent. This information will be used whenever possible to help us to explain the findings reported in the following section.

5.5 Data Analysis

The Perception of Sentence Modality Test data were analyzed first by observing the types of response provided by all listeners (statements, yes-no questions, Wh-questions), with the three intonational patterns combined. Descriptive statistics were obtained and the following will be reported: means, standard deviations, minimum and maximum scores, and percentages. In order to compare the means obtained for the three types of response, Friedman ${ }^{12}$ tests were used, given the fact that the data set is small and not normally distributed. Pair-wise comparisons were made by running Wilcoxon ${ }^{13}$ test. An additional analysis for the

12 The Friedman test is a non-parametric alternative to test the difference between several related samples (similar to a repeated-measures ANOVA) (LARSONHALL, 2010).

13 A non-parametric test used to compare pairs of means within groups when the data are not normally distributed (similar to a dependent-sample t-test) (LARSONHALL, 2010). 
Perception of Sentence Modality Test resulted from splitting the results according to intonational patterns and type of response. Because the data set is small, this analysis was done by calculating the percentages only.

The Perception of Intentionality Test data were analyzed by checking how often each of the three intonational patterns was perceived as one of the seven options displayed for the listeners in the test (see FIGURE 6). In order to calculate whether a certain intonational pattern would lead to specific types of response, data were rearranged. Thus, considering the low percentages obtained by most types of response, the intonation test results were analyzed statistically considering two categories: (a) Wants to know if (response number 1 in the test sheet) and (b) Other responses combined (responses from 2 to 7 in the test sheet). For this analysis, Wilcoxon tests were used separately for each intonational pattern tested. Finally, the Perception of Intentionality Test data were examined combining the responses for all types of intonational patterns and running a Wilcoxon test to compare the percentages obtained by the two categories of responses: (a) Wants to know if and (b) Other responses combined.

\section{Results and discussion}

This section displays the results and attempts to answer the two research questions which guide this study.

\subsection{Perception of Sentence Modality Test}

In the Perception of Sentence Modality Test, listeners had to decide whether the fifteen utterances produced by the BP speakers resembled (1) a statement, (2) a wh- question, or (3) a yes-no question, by attending only to prosodic cues. So far, all listeners are included together in the analysis, with no L1 dialect specification. We decided to keep them all, given the reduced amount of participants from each region. To observe how these three categories were perceived, Table 1 displays the descriptive statistics, which demonstrates a general performance for listeners with the 15 tokens the test contained. Later on, 
an analysis that takes into account the different contours of each token is presented (TABLE 3).

Table 1 - Listeners' general performance in the Perception of Sentence Modality Test

\begin{tabular}{ccccc}
\hline \multicolumn{5}{c}{ Perception of Sentence Modality Test (15 tokens) } \\
\hline Mean & $\%$ & SD & Min-Max \\
\hline Statements & 5.19 & $35 \%$ & 1.92 & $1-9$ \\
Yes-no & 6.13 & $43 \%$ & 2.21 & $2-12$ \\
Wh- & 2.74 & $22 \%$ & 1.57 & $0-6$ \\
\hline
\end{tabular}

Source: the authors.

Table 1 shows that BPSE listeners tended to consider most tokens as yes-no questions $(43 \%, M=6.13)$, followed by statements $(35 \%, M=$ $5.19)$, and wh- questions $(22 \%, M=2.74)$. The higher means for the yes-no questions can also be observed in the minimum and maximum scores ( 0 and 15, respectively) of listeners' individual performance. The maximum score for yes-no questions assigned by a listener was 12, whereas for statements and wh- questions it was 9 and 6, respectively, which signals greater variance on the perception of yes-no questions (SD $=2.21$ ). The least chosen category was wh- questions, which received 0 as its minimum score, meaning that the BPSE productions of yes-no intonational patterns in English were perceived as wh- questions to a small extent, which coincides nicely with the fact that no patterns for English wh- questions were included in the stimuli.

A Friedman test was run to observe if the differences in the means presented for listeners' performance with the three categories were significant. The test yielded a $p$-value of $p=.000$, which indicates significant differences. Moreover, to compare if the means obtained for each category were also significant when compared to a different tested category, Wilcoxon signed rank was run. The Wilcoxon tests showed that the differences reached statistical significance for all comparisons involving the Wh- question, but not for the Yes-no/Statement comparison, as can be observed in Table 2. This means that listeners did not distinguish yes-no questions from statements in their performance.

Table 2 - Wilcoxon signed rank for tested variables 


\begin{tabular}{clcc}
\hline & Yes-no / statements & $\begin{array}{c}\text { Wh- questions / } \\
\text { statements }\end{array}$ & $\begin{array}{c}\text { Wh- questions / } \\
\text { yes-no questions }\end{array}$ \\
\hline Z. & -1.086 & -3.802 & -4.053 \\
p. & .277 & .000 & .000 \\
\hline
\end{tabular}

Source: the authors.

Table 3 demonstrates how each of the different intonational patterns was perceived. It is important to restate that these three groups were formed according to the linguistic influence attested in the contour: English-L1 like (L*H\%), Brazilian-Portuguese like $\left(\mathrm{LH}^{*} \mathrm{~L} \%\right)$, and Interlanguage like $(\mathrm{L} * \mathrm{H} \%)$, as discussed in section 2.1 .

Table 3 - Perception of contours by BPSE

\begin{tabular}{lccc}
\hline & $\mathrm{L} * \mathrm{H} \%$ & $\mathrm{LH} * \mathrm{~L} \%$ & $\mathrm{~L} * ! \mathrm{H} \%$ \\
\hline Statement & $41 \%$ & $41 \%$ & $21 \%$ \\
Yes-no & $35 \%$ & $35 \%$ & $60 \%$ \\
Wh- & $24 \%$ & $24 \%$ & $19 \%$ \\
\hline
\end{tabular}

* English-L1 like - L*H\%; Brazilian-Portuguese like - LH*L\%;

Interlanguage like $-\mathrm{L} * ! \mathrm{H} \%$.

Source: the authors.

Sentences that contained both English-L1-like contour ( $\mathrm{L}^{*} \mathrm{H} \%$ ) and BP-like contour ( $\left.\mathrm{LH}^{*} \mathrm{~L} \%\right)$ were mostly perceived as statements by BPSE listeners $(41 \%)$. Thus, listeners were not attuned to the differences in intonation between these two categories, and there was a tendency to consider the tested sentences as statements. Yes-no and whquestions had the same percentages in both $\mathrm{L}^{*} \mathrm{H} \%$ and $\mathrm{LH}^{*} \mathrm{~L} \%$ ( $\mathrm{YN}=$ $35 ; \mathrm{WH}=24 \%$ ) and, thus, were chosen the least. Moreover, as there were no wh- contours included in the Perception of Sentence Modality Test, for both $\mathrm{L}^{*} \mathrm{H} \%$ and $\mathrm{LH}^{*} \mathrm{~L} \%, 24 \%$ are considered misperceptions of yes-no questions.

Different perception results were garnered for sentences that presented Interlanguage-like contour $\left(\mathrm{L}^{*} ! \mathrm{H} \%\right)$. There was a tendency for listeners to perceive these utterances as yes-no questions $(60 \%)$, 
followed by statements $(21 \%)$, and wh-questions $(19 \%)$. Thus, results demonstrate that $\mathrm{L}^{*} \mathrm{H} \%$ and $\mathrm{LH}^{*} \mathrm{~L} \%$ were overall perceived as statements by BPSE, while $\mathrm{L} * \mathrm{H} \%$ was surprisingly perceived as yes-no questions. The interlanguage-like pattern $\left(\mathrm{L}^{*} ! \mathrm{H} \%\right)$ was perceived as a yes/no question more often than was the native-like pattern $\left(\mathrm{L}^{*} \mathrm{H} \%\right)$ (25\% more often).

Results did not confirm Hypothesis 1, which predicted that neither $\mathrm{L}^{*} \mathrm{H} \%$ nor $\mathrm{L} * \mathrm{H} \%$ would be perceived as questions, given that BP intonational patterns for questions (both yes-no and wh-) have a low boundary tone. The perception of these two contours showed different behaviors. On the one hand, $\mathrm{L}^{*} \mathrm{H} \%$ partially confirmed $\mathrm{H} 1$, since it was perceived as a yes-no question to a little extent (only $35 \%$ of the times). A tentative explanation for this is that some BPSE taking part in the study may have been aware of the differences on the intonation of yes-no questions in English and were struggling to hear the rising intonation, succeeding $35 \%$ of the times. On the other hand, $\mathrm{L}^{*} ! \mathrm{H} \%$ goes counter the $\mathrm{H} 1$ prediction, since it was surprisingly mostly perceived as a yes-no question $(60 \%)$. Speculatively, this finding may be explained by the possibility that BPSE may have this underlying phonological representation for yes-no questions in English, which was also found to be representative of a developing intonational contour in the speakers' production (PASSARELLA-REIS, 2014). Further investigation is needed in order to draw some more definite conclusions.

Taking into consideration that the $\mathrm{PB}$ intonational pattern for neutral yes-no questions is $\mathrm{LH}^{*} \mathrm{~L} \%$, Hypothesis 2 , which predicted that $\mathrm{LH}^{*} \mathrm{~L} \%$ would mostly be perceived as questions, was not confirmed. The questions under the notation $\mathrm{LH}^{*} \mathrm{~L} \%$ were mostly perceived as statements. This may be explained by the possibility that these listeners were aware of the intonational patterns for questions and were also aware of a high boundary tone for English yes-no questions, recognizing the $\mathrm{L} \%$ as being mostly a representative of an intonational pattern other than that of yes-no (e.g., that of statements). From speculation, we can suppose that as a low boundary tone $(\mathrm{L} \%)$ is way more frequent in $\mathrm{BP}$, it was easier to be perceived, which yielded the recognition of the questions under the notation $\mathrm{LH}^{*} \mathrm{~L} \%$ as being mostly statements $(41 \%$ of the times). 
As the data set contained two utterances produced by a NorthAmerican speaker of English (NSE), we can compare the results regarding the perception of the yes-no question utterances produced by the BPSE and the NSE. As Table 4 shows, the yes-no questions produced by the NSE were perceived as such $(67.7 \%)$, which indicates that listeners were mostly attuned to the $\mathrm{L} * \mathrm{H} \%$ pattern when it was produced by the NSE. However, Table 4 also shows that the listeners had difficulties perceiving the intonation contour of the statement produced by the NSE, which was most often identified as a statement (45.2\%), but often misperceived as a question as well. All in all, these results confirm that the listeners face difficulties when asked to identify English intonational patterns, at least when they are presented with stimuli that contain suprasegmental information only. Moreover, the fact that the listeners performed differently with the $\mathrm{L}^{*} \mathrm{H} \%$ pattern produced by the BPSE and the NSE suggests that even when segmental information is erased from the stimuli, other speakers' pronunciation features may remain and somehow affect listeners' performance. Yet, although the pre-head and head of the utterances were not analyzed, it is likely that some slight intonational differences located in those parts of the utterances might exist and exert some influence on how they are perceived. Further research could include an analysis of the tones located in the head and pre-head in order to shed some light into understanding why the differences in performance were found.

Table 4 - Listeners' perceptions of the NSE intonational patterns

\begin{tabular}{lll}
\hline & $\mathrm{LH} * \mathrm{~L} \%$ & $\mathrm{~L} * \mathrm{H} \%$ \\
\hline Statement & $45.2 \%$ & $9.7 \%$ \\
Yes-no & $32.3 \%$ & $67.7 \%$ \\
Wh- & $22.6 \%$ & $22.6 \%$ \\
\hline
\end{tabular}

Source: the authors.

It is important to highlight, however, that although BPSE listeners might be aware of the intonational patterns tested, there was some variation on how the nonoptimal productions were perceived, not only as yes-no but also as statements and wh- questions (specially for 
LH*L\%). This may affect the way these questions are interpreted. This issue is addressed in Section 5.2.

\subsection{Perception of Intentionality Test}

As demonstrated by Figure 6, in the intentionality task, listeners had to decide about the intention/mood behind speakers' utterances. Table 5 provides the results for each intonational pattern tested.

Table 5 - Results for the Perception of Intentionality Test according to each contour

\begin{tabular}{llll}
\hline & $\begin{array}{ll}\mathrm{L}^{*} ! \mathrm{H} \% \\
\mathrm{~N}=155\end{array}$ & $\begin{array}{l}\mathrm{LH} * \mathrm{~L} \% \\
\mathrm{~N}=155\end{array}$ & $\begin{array}{l}\mathrm{L} * \mathrm{H} \% \\
\mathrm{~N}=155\end{array}$ \\
\hline 1 Wants to know IF & $71.61 \%$ & $69.03 \%$ & $63.22 \%$ \\
2 Is assuming that & $14.83 \%$ & $10.97 \%$ & $10.97 \%$ \\
3 Criticizing the fact that & $2.58 \%$ & $1.29 \%$ & $1.93 \%$ \\
4 Is doubting the fact that & $4.51 \%$ & $5.81 \%$ & $12.90 \%$ \\
5 Is surprised that & $2.5 \%$ & $9.68 \%$ & $5.81 \%$ \\
6 Is making fun of the fact & $3.22 \%$ & $1.93 \%$ & $3.87 \%$ \\
7 Something else & $0,5 \%$ & $1.29 \%$ & $1.29 \%$ \\
\hline
\end{tabular}

${ }^{a}$ Something else $=$ is hesitating, wants to be sure that, is seducing the listener, is inviting the listener to, is being ironic, is not interested, thinks it is logical that.

Source: the authors.

$\mathrm{L}^{*} ! \mathrm{H} \%$, the interlanguage-like contour, in the Perception of Sentence Modality Test was mostly perceived as yes-no questions $(60 \%)$, which is in tune with the results obtained with the Perception of Intentionality Test (71.61\%), as listeners considered that, by using this pattern, speakers were asking a question whose answer could be either affirmative or negative, that is, a neutral yes-no question most of the times (e.g., "is that OK with you?"). Another interpretation for this intonational pattern was that the speaker was assuming rather than asking 
a confirmation for some information (14.83\%). Sosa, Nunes and Seara (2013) found that a high boundary tone $(\mathrm{H} \%)$ for yes-no questions in BP may refer to a question whose answer is expected to be positive. By taking this into account, it can be proposed that, in $15 \%$ of the cases, listeners interpreted that the speakers were assuming (by stating) some information rather than asking, by relying on their L1 intonational patterns. Although the boundary tone was a downstep rise $(! \mathrm{H})$, it seemed to be high enough to yield this interpretation. This agrees nicely with the Perception of Sentence Modality Test results, which shows that $21 \%$ of the occurrences of this contour were perceived as statements. Finally, the interlanguage-like contour $\left(\mathrm{L}^{*} ! \mathrm{H} \%\right)$ was also interpreted as showing "criticism", "incredulity", "surprise", "tease" and "lack of interest" to a smaller extent $(7.35 \%$ of the cases altogether). The Wilcoxon test demonstrated that the differences in interpretation for this contour were significant $(\mathrm{p}=.001)$, as can be drawn from Table 6 .

Brazilian-Portuguese-like $\mathrm{LH}^{*} \mathrm{~L} \%$ was mostly interpreted as neutral yes-no questions $(69.03 \%)$. The fact that the contour $\mathrm{LH}^{*} \mathrm{~L} \%$ is also the intonational pattern for neutral yes-no questions in BP may have exerted some influence on listeners' interpretation of this pattern as a neutral question, even when knowing that the intonational pattern for neutral yes-no questions in English is $\mathrm{L}^{*} \mathrm{H} \%$ (knowledge that we speculatively assumed, given that most listeners were English teachers/professors and/or candidates to a degree in English). In the Perception of Sentence Modality Test, LH*L\% tokens had a smaller percentage, as only $35 \%$ of them were considered to be yes-no questions. Additionally, the pattern $\mathrm{LH}^{*} \mathrm{~L} \%$ presents some variation as regards listeners' evaluations. Listeners also considered that speakers were (1) assuming that (10.97\%), (2) showing surprise (9.68\%), (3) doubting $(5.81 \%)$, (4) making fun $(1.93 \%)$, and (5) criticizing $(1.29 \%)$ rather than asking questions. In the Perception of Sentence Modality Test, $41 \%$ of $\mathrm{LH}^{*} \mathrm{~L} \%$ utterances were perceived as statements. One possible explanation is that the many options included in the Perception of Intentionality Test might have misled listeners to interpret intentions that actually could not be conveyed by this pattern. This would account for the variation in listeners' intentionality responses and also for the fact that these responses do not tally with the way that this pattern was 
mostly perceived as statements. Research on yes-no questions with a low boundary tone (L\%) have shown that these utterances refer to questions that (1) are a request for action (Can we talk about job things now?), (2) are observations (Do you have a cold?) (HEDBERG; SOSA, 2011), (3) are assumptions (PASSARELLA-REIS, 2014), and (4) are questions whose answer is expected to be positive (HUYNH, 2012). Therefore, another possible explanation is that the low boundary tone may have led the listeners' interpretations by making them follow their L1 intuition, not by chance. Finally, by having access to the questions in both audio and written forms, participants ended up having one more form of input to rely on, thus being able to base their interpretations on something else rather than the intonational pattern itself, that is, they may have turned their attention to syntactic clues and disregarded the intonation information. The Wilcoxon test demonstrated that the differences in interpretation for this contour were significant $(p=.000)$, as can be observed in Table 6.

English-L1-like $\mathrm{L} * \mathrm{H} \%$ contours were also mostly interpreted as neutral yes-no questions (63.22\%) in the Perception of Intentionality Test. This pattern was perceived as a neutral yes-no question to a smaller extent (35\% of tokens) in the Perception of Sentence Modality Test. Also, listeners interpreted that $\mathrm{L} * \mathrm{H} \%$ conveyed that speakers were (1) doubting (12.97\%), (2) assuming something (10.97\%), (3) showing surprise $(5.81 \%)$, (4) making fun $(3.87 \%)$, and (5) criticizing $(1.93 \%)$ rather than asking a neutral question. Given that BP yes-no questions present more tonal movement in the intonational pattern than English yes-no questions, the tendency for listeners' variability in responses could be explained by the fact that only one rise towards the boundary tone is not enough to lead listeners to perceive this pattern as yes-no questions, and thus, (1) it tends to be misperceived as statements (41\%) and, (2) it may confuse listeners as to speakers' intent (36.77\%). ${ }^{14}$ Research has shown that BP yes-no questions with a high boundary tone $(\mathrm{H} \%)$ refer to a question that shows (1) emphasis (MORAES, 2008), (2) kindness (PASSARELLA-REIS, 2014), or (3) expectations for a positive

14 Percentage calculated from Table 4, by summing up cases 2 to 7 , that is, every instance in which an utterance under $\mathrm{L} * \mathrm{H} \%$ was not interpreted as a yes-no question. 
answer (SOSA; NUNES; SEARA, 2013). Another tentative explanation here is that listeners' L1 may have exerted some influence on their interpretations for the optimal production of yes-no questions by BPSE. However, drawing definite conclusions is still not possible due to a dearth of studies investigating interpretations of yes-no questions with non-canonical intonational patterns in BP. Wilcoxon tests showed that the differences in interpretation for this contour reached statistical significance $(\mathrm{p}=.008)$, as can be drawn from Table 6 .

Table 6 - Wilcoxon signed rank for tested variables:

Neutral yes-no versus other interpretations

\begin{tabular}{clll}
\hline & $\mathrm{L} * ! \mathrm{H} \%$ & $\mathrm{LH}{ }^{*} \mathrm{~L} \%$ & $\mathrm{~L} * \mathrm{H} \%$ \\
\hline Z. & -3.456 & -3.842 & -2.648 \\
p. & .001 & .000 & .008 \\
\hline
\end{tabular}

Source: the authors.

As the experimenters observed a tendency for listeners to interpret the tokens as yes-no questions, Wilcoxon Signed Rank was run, taking into account the number of responses for yes-no questions and the number of responses which encompassed different interpretations, irrespective of intonational contours. The test confirmed that the differences between the two interpretations (yes-no and something else) reached statistical significance $(z=-3.657 ; p=.000)$. Table 7 displays the interpretations of listeners irrespectively of the intonational patterns involved. Most yes-no questions were interpreted as real questions, that is, as neutral yes-no questions $(67.96 \%)$, while $32.04 \%$ of tokens were interpreted as having manifold meanings. It seems that the three different intonational patterns did not have a strong influence on how these questions were interpreted, since together they conveyed a real question more than $65 \%$ of the cases (TABLE 7 ), and separately more than $60 \%$ of the cases (TABLE 5). 
Table 7 - Results for the Perception of Intentionality Test according to each intention

\begin{tabular}{lll}
\hline Interpretations & $\mathrm{N}$ & $\%$ \\
\hline 1 Wants to know IF & 316 & 67.96 \\
2 Is assuming that & 57 & 12.26 \\
3 Criticizing the fact that & 9 & 1.93 \\
4 Is doubting the fact that & 36 & 7.74 \\
5 Is surprised that & 28 & 6.02 \\
6 Is making fun of the fact & 14 & 3.01 \\
7 Something else & 5 & 1.08 \\
\hline${ }^{\mathrm{a}}$ Something else
\end{tabular}

${ }^{\text {a }}$ Something else $=$ is hesitating, wants to be sure that, is seducing the listener, is inviting the listener to, is being ironic, is not interested, thinks it is logical that. Source: the authors.

Hypothesis 3 predicted that both $\mathrm{L} * \mathrm{H} \%$ and $\mathrm{L} * \mathrm{H}$ would mostly have listeners to infer that speakers' intentions were other than asking a neutral question, given that the low nuclear accent followed by a rise $\left(\mathrm{L}^{*} \mathrm{H} \%\right.$ or $\left.\mathrm{L} * \mathrm{H} \%\right)$ would not be recognized as a real question by a $\mathrm{BP}$ listener, but it was not confirmed. Most tokens with both intonational patterns were interpreted as neutral questions $(63.22 \%$ and $71.61 \%$, respectively). Differences reached statistical significance in all categories $(\mathrm{p}<.05)$.

Hypothesis 4 predicted that listeners would interpret questions under $\mathrm{LH} * \mathrm{~L} \%$ as neutral questions, because they would base their interpretations on their L1 intonational pattern for BP yes-no questions. This was confirmed, since $69.03 \%$ of the tokens were interpreted as neutral questions and the differences reached statistical significance $(\mathrm{p}=$ $.000)$.

Nonetheless, it is undeniable that a considerable number of different interpretations arose mainly for $\mathrm{LH}^{*} \mathrm{~L} \%(30.97 \%)$ and $\mathrm{L} * \mathrm{H} \%$ $(36.77 \%)$ which are intonational patterns for neutral BP and English yesno questions, respectively, followed by $\mathrm{L} * \mathrm{H} \%(28.14 \%)$ which is a new intonational pattern recognized as belonging to BP learners' interlanguage.

15 Wilcoxon tests showed that the differences were not statistically significant, though $(\mathrm{p}>.05)$. 
Interestingly, similar results were found in the Perception of Sentence Modality Test, whereby $\mathrm{LH}^{*} \mathrm{~L} \%$ and $\mathrm{L} * \mathrm{H} \%$ were perceived as yes-no questions to a little extent ( $35 \%$ of the cases), while $\mathrm{L}^{*} ! \mathrm{H} \%$ was perceived as yes-no questions most of the times (60\%). These results may signal that the underlying representation for yes-no questions for these BP listeners was $\mathrm{L}^{*} ! \mathrm{H} \%$, which coincides well with the fact that listeners interpreted $\mathrm{L} * ! \mathrm{H} \%$ tokens as real questions most of the time. With regard to $\mathrm{LH}^{*} \mathrm{~L} \%$ and $\mathrm{L} * \mathrm{H} \%$, these two intonational patterns may have categories formed in their phonological systems and listeners still struggle when they have to make decisions regarding both patterns.

Again we can compare the results obtained for the BPSE speakers with the results obtained for the NSE. Regarding the Perception of Intentionality Test, Table 8 shows that the Brazilian listeners seem to have difficulty perceiving the intentionality of the yes-no question patterns (but not of the statements), as the listeners inferred that the NSE intention was other than asking a neutral question $(74.2 \%)$. These results suggest an overall difficulty perceiving the intentionality of the English yes-no questions produced by the NSE. However, this conclusion goes against the findings for the Perception of Sentence Modality Test, in which the listeners successfully identified the yes-no question pattern with the NSE data about $70 \%$ of the time, and against the results for the Perception of Intentionality Test with the BPSE data (listeners interpreted the $\mathrm{L} * \mathrm{H} \%$ tokens produced by BPSE as neutral questions almost $70 \%$ of the time).

Table 8 - Listeners' interpretations of the NSE tokens

\begin{tabular}{ccc}
\hline & $\mathrm{LH} * \mathrm{~L} \%$ & $\mathrm{~L} * \mathrm{H} \%$ \\
\hline Wants to know if & $6.5 \%$ & $25.8 \%$ \\
Something else & $93.5 \%$ & $74.2 \%$ \\
\hline
\end{tabular}

Source: the authors.

One could also wonder whether the variety of interpretations provided in the Perception of Intentionality Test (7 items) caused the listeners to be confused about which option to choose when listening to the NSE tokens. Nonetheless, test design did not have a similar negative 
effect on the listeners' performance with the BPSE data. Further investigation is required to pursue these issues.

\section{Final remarks}

The current study investigated how BPSE perceive yes-no questions that carry different prosodic information, and how these listeners evaluate the intentions behind each question, taking into account their prosodic cues. Research has shown that a low boundary tone for yes-no questions can yield manifold interpretations (PASSARELLA-REIS, 2014; HEDBERG; SOSA, 2011; HUYNH, 2012). Results showed that even though listeners and speakers share the $\mathrm{L} 1$, they interpreted $\mathrm{LH} * \mathrm{~L} \%$ as a neutral question but also as a question meaning something else. These kinds of interpretations may impact conversations held between listeners and speakers in contexts where only acoustic information is available (on a phone call, for instance).

It goes without saying that talking to someone in English when both parties have the same L1 is uncommon. Nonetheless, "due to various social, political, and historical circumstances, non-native talkers who share a native language may sometimes communicate in a shared foreign language" (BENT; BRADLOW, 2003, p. 1608). The present study shows that the nonoptimal intonational patterns produced by the BP speakers can exert some influence on interpretations by BP listeners. This influence when listeners from different L1 backgrounds are involved can be much higher. Thus, further research should investigate how these intonational patterns are interpreted by listeners of manifold nationalities, including English.

As concerns the limitations of the present study, it is noteworthy to acknowledge that the Perception of Intentionality Test had too many options, and this might have misled listeners to choose intentions / moods that did not correspond to the intonational pattern demonstrated in the utterance, which resulted in much variation in listeners' responses. Thus, the experimenters believe that only the options "wants to know if" and "is assuming that" should be presented in the test, along with the possibility for listeners to fill in their own answer. Notwithstanding, 
Pierrehumbert and Hirschberg (1990) claim that the meaning of a speaker's attitude is better understood when interpreted within a context, rather than the utterance itself representing its meaning. Nonetheless, due to the test format and also the purposes of this study, such approach could not be followed, and single sentences, presented without a broader context, were used. Some problems also occurred with the website used for data collection as listeners did not have enough characters to type in their comments with some questions in the on-line questionnaire. Another aspect worth of attention regards listeners' L1 dialect. To conduct the analysis in the current paper, we did not separate them according to region as a limited amount of participants completed all tasks (plus questionnaires). For further research, more listeners from specific regions can participate in the study and then allow us to conduct specific analyses according to listeners' L1 dialect, as it can account greatly for language variation (CLOPPER; PISONI, 2005).

To warrant future research, the nonoptimal segmental production of the tokens used in the tests shall be acknowledged. In order to evaluate the impact these might have on listeners' judgments, an experiment on intelligibility could provide insight on the phonological aspects that are likely to hinder listeners' understanding of utterances. It would also be possible to draw assumptions on how this construct influences perception and leads to harsher judgments regarding speakers' intentions. More variables related to the listeners could be investigated, such as amount of experience with the tested language, and later on compared to their performance in the study tasks. Thus, the researchers could develop a more mature view on the many interacting variables, relating either to the learner or to the context, which dynamically influence the ongoing process of language learning. Moreover, further research should also examine listeners' performance by comparing data from NSE and of other L1 backgrounds in order to understand the extent to which experimental design may be influencing the results yielded by the Perception of Sentence Modality Test and the Perception of Intentionality Test.

The results presented here shed light on the complexity involved in speech perception and the way it is processed especially in contexts in which only acoustic and non-visual information is available (listening 
tasks, for example). Also, the present study begins a brainstorm on the way unexpected intonational pattern realizations may be interpreted by different listeners and calls for the importance of drawing learners' attention to intonational aspects in English classes in Brazil.

\section{Acknowledgements}

We would like to express our deepest gratitude to Hallthmann Lima Passarella dos Reis for the creation of the website, as well as to all participants of the present study, who made our achievements possible. Our gratitude is also extended to Professor Izabel Seara for helping manipulate the stimuli, and to the anonymous reviewers for their valuable contributions.

\section{References}

BECKMAN, M. E.; VENDITTI, J. J. Tone and intonation. In: HARDCASTLE, W. J; LAVER, J.; GIBBON, F. E. The handbook of phonetic sciences. $2^{\text {nd }}$ edition. Blackwell Publishing, 2013.

BENT, T.; BRADLOW, A. R. The interlanguage speech intelligibility benefit. The Journal of the Acoustical Society of America, v. 114, n. 3, p. 1600-1610, 2003. <http://dx.doi.org/10.1121/1.1603234>

CATFORD, J. C. A Linguistic Theory of Translation: an Essay in Applied Linguistics. London: Oxford University Press, 1965.

CLOPPER, C. G.; PISONI, D. B. Perception of dialect variation. In: PISONI, D. B.; REMEZ, R. E. The handbook of speech perception. $1^{\text {st }}$ edition. Blackwell Publishing, 2005.

$<$ http://dx.doi.org/10.1002/9780470757024.ch13>

COLAMARCO, M.; MORAES, J. A. Emotion expression in speech acts in Brazilian Portuguese: Production and Perception. SPEECH PROSODY, 2008, May 6-9, ISCA Arquive: Campinas. p. 717-719, 2008.

CRYSTAL, D. A dictionary of linguistics and phonetics. Blackwell 
Publishing. 2008.<http://dx.doi.org/10.1002/9781444302776>

GONÇALVES, A. R. In search of speech intelligibility: the case of English high front vowels. Dissertação (Mestrado em Inglês). 170f. Universidade Federal de Santa Catarina. Florianópolis: Brasil, 2014.

HEDBERG, N.; SOSA, M. J. A Unified Account of the Meaning of English Questions with Non-Canonical Intonation. INTERNATIONAL SEMINAR ON PROSODIC INTERFACES, November 25-27, 2011, New Delhi, India. Proceedings... New Delhi, India: Jawaharlal Nehru University, 2011.

HEDBERG, N.; SOSA, M. J.; FADDEN, L. Meanings and Configurations of Questions in English. SPEECH PROSODY 2004, Nara, Japan. Proceedings... Nara, Japan, 2004. Available at: $<$ http://www.sfu.ca/ hedberg/Hed_Sos_Fad_Fin_2004.pdf $>$.

HIRSCHBERG, J., D. LITMAN, J. PIERREHUMBERT AND G. WARD. Intonation and the Intentional Structure of Discourse. INTERNATIONAL JOINT CONGRESS ON ARTIFICIAL INTELLIGENCE, 10, 1987, Milan, Italy. Proceedings... Milan, Italy, August 1987.

HUYNH, L. T. Question intonation patterns in A Real-life Conversation and in Textbook Dialogs. Hanoi, Vietnam: Education Publishing, 2012. Available at: $<$ http://www.hpu.edu/CHSS/LangLing/TESOL/Professional Development/201210_TWPfall12/TESOL_WPS_2012_Huynh.pdf $>$.

LADD, D. R. Phonological representation of pitch in the autosegmentalmetrical theory. In: __ Intonational phonology. Cambridge: Press Syndicate of the University of Cambridge, 79-112. 1996.

. Fundamental concepts of the autosegmental-metrical theory. In: . Intonational phonology. Cambridge: Press Syndicate of the University of Cambridge, 43-84. 2008.

LARSON-HALL, J. A Guide to Doing Statistics in Second Language Research Using SPSS. New York and London: Routledge, 2010.

MORAES, J. A. The pitch accents in Brazilian Portuguese analysis by synthesis. SPEECH PROSODY 2008, 4, Campinas, Brazil. 
Proceedings... Campinas, SP, may 2008. Disponível em: $<$ http://www.isca-speech.org/archive/sp2008/papers/sp08_389.pdf $>$.

PASSARELLA-REIS, H. L. English research. 2013. Disponível em: $<$ www.leonicepassarella.pro.br $>$.

PASSARELLA-REIS, L. Descendo or Rising? Intonational Patterns in American English and Brazilian Portuguese Polar Questions by Brazilian Speakers. Revista X, v. 1, p. 1-22, 2014.

PIERREHUMBERT, J. The Phonology and Phonetics of English Intonation. 1980. Thesis ( $\mathrm{PhD})$ - Massachusetts Institute of Technology, Cambridge, MA, 1980.

PIERREHUMBERT, J.; HIRSCHBERG, J. The Meaning of Intonational contours in the Interpretation of Discourse. In: COHEN, P.; MORGAN, J.; POLLACK, M. (Ed.). Intentions in Communication. Cambridge MA: MIT Press, 1990. p. 271-311.

SELINKER, L., Interlanguage. International Review of Applied Linguistics in Language Teaching, v. 10, n.3. p.209-231, 1972.

$<$ http://dx.doi.org/10.1515/iral.1972.10.1-4.209>

SMILJANIC, R.; BRADLOW, A. R. Bidirectional clear speech perception benefit for native and high proficiency non-native talkerlistener pairs: Intelligibility and accentedness. Journal of the Acoustical Society of America, 130(6), p. 4020-4031, 2011.

$<$ http://dx.doi.org/10.1121/1.3652882>

SOSA, J. M., NUNES, V.G., SEARA, I.C. Variação prosódica das sentenças interrogativas totais no falar catarinense: um estudo experimental. Leitura, v. 2, n. 52, p. 139-163, 2013.

ZAMPINI, M. L. L2 speech production research: findings, issues, and advances. In: HANSEN EDWARDS, J. G.; ZAMPINI, M. L. (Ed.). Phonology and Second Language Acquisition. Amsterdam: John Benjamins. 2008. p. 219-249. <http://dx.doi.org/10.1075/sibil.36.11zam> 
APPENDIX A - Perception Test tokens and their corresponding intonational patterns

\begin{tabular}{|c|c|c|c|}
\hline Audios & Questions & Speaker & Notations* \\
\hline 01 & Do you like movies? & $\mathrm{BP}$ & LH*L\% \\
\hline 02 & Do you like rock? & $\mathrm{BP}$ & $\mathrm{L} * ! \mathrm{H} \%$ \\
\hline 03 & Did you like the movie? & $\mathrm{BP}$ & $\mathrm{LH}^{*} \mathrm{~L} \%$ \\
\hline 04 & Is that OK with you? & $\mathrm{BP}$ & $\mathrm{L} * \mathrm{H} \%$ \\
\hline 05 & Would you like to join me some day? & $\mathrm{BP}$ & $\mathrm{L} * ! \mathrm{H} \%$ \\
\hline 06 & Do you know William? & $\mathrm{BP}$ & $\mathrm{LH}^{*} \mathrm{~L} \%$ \\
\hline 07 & Are you Brazilian? & $\mathrm{BP}$ & $\mathrm{LH}^{*} \mathrm{~L} \%$ \\
\hline 08 & Do you live alone? & $\mathrm{BP}$ & $\mathrm{L} * \mathrm{H} \%$ \\
\hline 09 & Would you like to go? & BP & $\mathrm{L} * \mathrm{H} \%$ \\
\hline 10 & Do you listen to music? & $\mathrm{BP}$ & LH*L\% \\
\hline 11 & Would you like to listen to it? & $\mathrm{BP}$ & $\mathrm{L} * \mathrm{H} \%$ \\
\hline 12 & Do you like sports? & $\mathrm{BP}$ & $\mathrm{L} * \mathrm{H} \%$ \\
\hline 13 & Are you a student? & $\mathrm{BP}$ & $\mathrm{L} * ! \mathrm{H} \%$ \\
\hline 14 & Do you like comedies? & $\mathrm{BP}$ & $\mathrm{L}^{*} ! \mathrm{H} \%$ \\
\hline 15 & Do you like movies? & $\mathrm{BP}$ & $\mathrm{L}^{*} ! \mathrm{H} \%$ \\
\hline 16 & You're on vacation... & NSE & $\mathrm{LH}^{*} \mathrm{~L} \%$ \\
\hline 17 & Are you a student? & NSE & $\mathrm{L} * \mathrm{H} \%$ \\
\hline
\end{tabular}

* English L1 like - L*H\%; Brazilian Portuguese like - LH*L\%;

Interlanguage like $-\mathrm{L}^{*} ! \mathrm{H} \%$. 
RELIN, v. 24, n. 1, 2016. 
